\title{
Influences of Fluorine Substituents on Iminopyridine Fe(II)- and Co(II)-Catalyzed Isoprene Polymerization
}

\author{
Guangqian Zhu ${ }^{1}$, Xianhui Zhang ${ }^{2,3}$, Mengmeng Zhao ${ }^{2}$, Liang Wang ${ }^{2}$, Chuyang Jing ${ }^{2,3}$, \\ Peng Wang $1, *$, Xiaowu Wang $2, *$ (i) and Qinggang Wang ${ }^{2, *}$ (i) \\ 1 School of Chemical and Environmental Engineering, Shandong University of Science and Technology, \\ Qingdao 266590, China; m18306422553@163.com \\ 2 Key Laboratory of Biobased Materials, Qingdao Institute of Bioenergy and Bioprocess Technology, \\ Chinese Academy of Sciences, Qingdao 266101, China; zhangxh@qibebt.ac.cn (X.Z.); \\ zhaomm@qibebt.ac.cn (M.Z.); wangliang@qibebt.ac.cn (L.W.); jingcy@qibebt.ac.cn (C.J.) \\ 3 University of Chinese Academy of Sciences, Beijing 100049, China \\ * Correspondence: pengwang@sdust.edu.cn (P.W.); wangxw@qibebt.ac.cn (X.W.); \\ wangqg@qibebt.ac.cn (Q.W.); Tel.: +86-158-0658-1125 (Q.W.)
}

Received: 15 July 2018; Accepted: 18 August 2018; Published: 22 August 2018

\begin{abstract}
A series of iminopyridine complexes of $\mathrm{Fe}(\mathrm{II})$ and $\mathrm{Co}(\mathrm{II})$ complexes bearing fluorinated aryl substituents were synthesized for the polymerization of isoprene. The structures of complexes $3 \mathbf{a}$, $\mathbf{2} \mathbf{b}$ and $\mathbf{3} \mathbf{b}$ were determined by $\mathrm{X}$-ray diffraction analysis. Complex $\mathbf{3} \mathbf{a}$ contained two iminopyridine ligands coordinated to the iron metal center forming an octahedral geometry, whereas $\mathbf{2} \mathbf{b}$ adopted a chloro-bridged dimer, and $\mathbf{3 b}$ featured with two patterns of cobalt centers bridged via chlorine atoms. Complexes $\mathbf{2} \mathbf{b}$ and $\mathbf{3} \mathbf{b}$ represented rare examples of chlorine bridged bimetallic Co(II) complexes. The fluorine substituents effects, particularly on catalytic activity and polymer properties such as molecular weight and regio-/stereo-selectivity were investigated when these complexes were employed for isoprene polymerization. Among the Fe(II)/methylaluminoxane (MAO) systems, the $4-\mathrm{CF}_{3}$ substituted iminopyridine $\mathrm{Fe}(\mathrm{II})$ complex 1a was found as a highly active isoprene polymerization catalyst exhibiting the highest activity of $10^{6} \mathrm{~g} \cdot(\mathrm{mol} \mathrm{of} \mathrm{Fe})^{-1} \cdot \mathrm{h}^{-1}$. The resultant polymer displayed lower molecular weight $\left(M_{\mathrm{n}}=3.5 \times 10^{4} \mathrm{~g} / \mathrm{mol}\right)$ and moderate polydispersity index (PDI = 2.1). Furthermore, the ratio of cis-1,4-/3,4 was not affected by the F substituents. In the series of $\mathrm{Co}(\mathrm{II}) / \mathrm{AlEt}_{2} \mathrm{Cl}$ binary systems, complexes containing electron-withdrawing $\mathrm{N}$-aryl substituents $\left(\mathrm{R}=4-\mathrm{CF}_{3}, 2,6-2 \mathrm{~F}\right)$ afforded higher molecular weights polyisoprene than that was obtained by the complex containing electron-donating $\mathrm{N}$-alkyl substituents $(\mathrm{R}=$ octyl $)$. However, ternary components system, complex/MAO/[Ph$\left.{ }_{3} \mathrm{C}\right]\left[\mathrm{B}\left(\mathrm{C}_{6} \mathrm{~F}_{5}\right)_{4}\right]$ resulted in low molecular weight polyisoprene $\left(M_{\mathrm{n}}<2000\right)$ with high trans-1,4-unit $(>95 \%)$.
\end{abstract}

Keywords: iminopyridine ligands; $\mathrm{Fe}(\mathrm{II})$; $\mathrm{Co}(\mathrm{II})$ complexes; isoprene polymerization; fluorinated aryl substituents

\section{Introduction}

Synthetic polyisoprene displays significant interests in material application, which has been introduced to replace the natural rubber in some extent [1]. Polyisoprene can be obtained with diverse regio- and/or stereo-selectivities such as cis-1,4-/trans-1,4-/3,4-/1,2-polyisoprene. The physical properties are strongly related to the microstructure of polyisoprene. For instance, cis-1,4-polyisoprene shows similar characteristics particularly stereo and chemical compositions and thereby mechanical properties with the natural rubber which has been largely applied to tires [2]. High trans-1,4-polyisoprene is more alike to the natural gutta-percha [3], which is widely employed in 
shape memory functional materials. Furthermore, 3,4-polyisoprene is applied in wet skid resistance or low-rolling resistance tread due to its pendant groups [4]. Polyisoprene is generally produced via anionic or coordination polymerization [3,5]. In coordination polymerization, transition metal catalyzed polymerization has received considerable attention both from industry and academia because of their high reactivity and selectivity. In the past decades, various selective diene polymerization catalysts were investigated using Ziegler-Natta Ti [6] or rare earth metal catalysts [3,7-13]. Since the discovery of late transition metal catalysts for olefin polymerization reported by Gibson [14] and Brookhart [15] in the late 1990s, a plethora of catalysts have been developed for the polymerization of various type of monomers. Due to the lower Lewis acidic nature and higher functional group tolerance, late transition metal, especially cheap and earth-abundant iron- and cobalt-based catalysts, have attracted extensive investigations in both $\alpha$-olefin and diene polymerization [16-26].

Despite iron- and cobalt-based catalysts in combination with alkylaluminium compounds for diene polymerization have been known for a long time, these structurally less-defined and multi-site catalysts often display low activity and produce polymers with poor stereoselectivity and broad molecular weight distribution, which results in poor mechanical properties. In order to gain better control of isoprene polymerization, including molecular weight, molecular weight distribution and stereoselectivity, academic and industrial researches have focused on well-defined organometallic single-site catalysts. Very recently, inspired by the Fe(II) bisiminopyridine complexes in ethylene polymerization, Ritter group [27] reported a ternary catalyst system, [iminopyridine Fe(II) complexes, alkyl aluminium and dealkylating reagent $\left.\left[\mathrm{Ph}_{3} \mathrm{C}\right]\left[\mathrm{B}\left(\mathrm{C}_{6} \mathrm{~F}_{5}\right)_{4}\right]\right]$ that showed high stereoselectivity for isoprene polymerization. The iron catalysts bearing electron donating imine groups afforded polymer with high trans-1,4 selectivity, while high cis-1,4 selectivity was obtained using the catalysts bearing electron-withdrawing imine group. In view of these findings, the authors proposed that higher electron density at the iron center favor trans-1,4 selectivity. Later, Chen et al. [28] reported Fe(II) and $\mathrm{Co}(\mathrm{II})$ complexes bearing bulky substituents. The complexes containing $\mathrm{N}$-aryl imine groups produced polymer in a higher yield than $\mathrm{N}$-alkyl imine groups, which potentially suggests that electron-withdrawing substituents lead to better monomer coordination and faster chain propagation.

In the present study, a series of iminopyridine $\mathrm{Fe}(\mathrm{II})$ and $\mathrm{Co}$ (II) complexes containing fluorinated aryl substituents were synthesized and employed in isoprene polymerization in combination with alkylaluminium (methylaluminoxane (MAO) or $\mathrm{AlEt}_{2} \mathrm{Cl}$ ) (Scheme 1). Both binary system and ternary system were investigated. The fluorine effects of the imine moiety on the catalytic activity, molecular weight as well as the regio- and/or stereoselectivity were investigated. The present study sheds light on how to control the isoprene polymerization through modifying the ligand framework and electronic effects of the $\mathrm{Fe}$ (II) and $\mathrm{Co}(\mathrm{II})$ complexes catalysts.

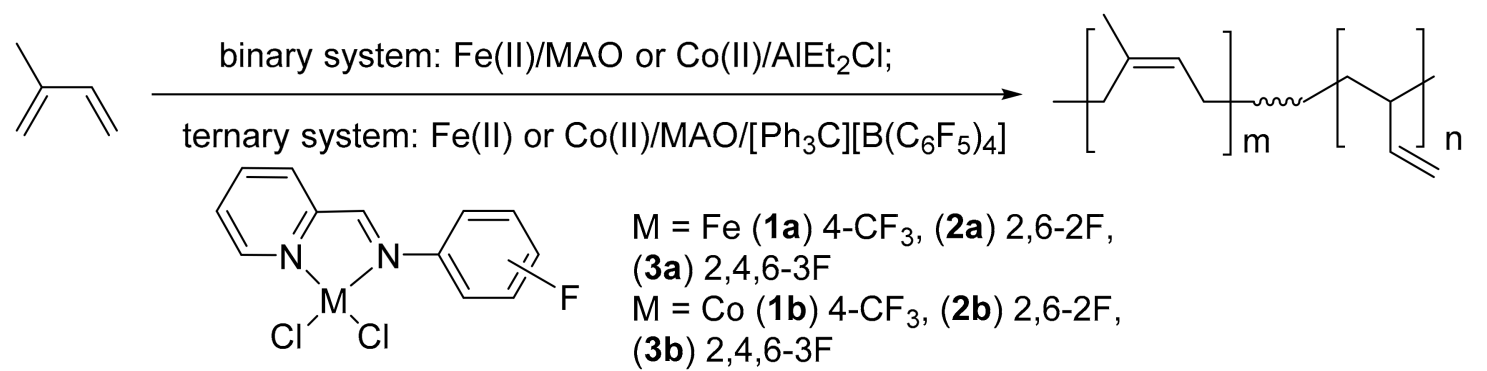

Scheme 1. Fluorinated-aryl-substituted iminopyridine Fe(II) and Co(II) complexes catalyzed isoprene polymerization. 


\section{Materials and Methods}

\subsection{General Information}

All manipulations of air and/or moisture sensitive compounds were performed using standard Schlenk technique. Toluene, dichloromethane, tetrahydrofuran (THF) and hexane were purchased from Sinopharm Chemical Reagent (Shanghai, China), dried over sodium benzophenone ketyl (toluene, THF) or calcium hydride $\left(\mathrm{CH}_{2} \mathrm{Cl}_{2}\right.$, hexane) and distilled under an argon atmosphere prior to use. The progress of the organic reactions was monitored by thin layer chromatography (TLC) using $0.2 \mathrm{~mm}$ Macherey-Nagel silica gel precoated plates (POLYGRAM SILG/UV254, haoranbio, Shanghai, China). ${ }^{1} \mathrm{H}$ and ${ }^{13} \mathrm{C}$ NMR spectra were recorded on a Bruker Avance III $400 \mathrm{MHz}$ spectrometer (Bruker, Karlsruhe, Germany) using $\mathrm{CDCl}_{3}$ (CIL, Andover, MA, USA) as solvent and trimethylsilane (TMS; $\mathrm{CIL}$, Andover, MA, USA) as internal reference. Chemical shifts and coupling constant are given in ppm and in $\mathrm{Hz}$ respectively. The abbreviations: $\mathrm{s}=$ singlet, $\mathrm{d}=$ doublet, $\mathrm{t}=$ triplet, $\mathrm{m}=$ multiplet were used to designate the multiplicities of signal. Attenuated total reflection-infrared (ATR-IR) spectroscopy was performed using Thermo Scientific Nicolet iN10 (Thermo Fisher Scientific Corporation, Waltham, MA, USA). Elemental analysis was carried out on Vario EL III elemental analyzer (Elementar Corporation, Hanau, Germany) at Shanghai Institute of Organic Chemistry, Chinese Academy of Sciences (Shanghai, China). Mass spectra for new organic compounds were measured using maXis II of Bruker Daltonics Corporation (Bruker Daltonics Corporation, Billerica, MA, USA), while for Fe(II) and Co(II) complexes were recorded by ACQUITYTM UPLC \& Q-TOF MS Premier (Waters, Milford, MA, USA) at Analytical Center of Shanghai Jiao Tong University (Shanghai, China). X-ray Diffraction data was collected on Smart 1000 diffractometer (Bruker, Karlsruhe, Germany) with Mo K-alpha X-ray source $(\lambda=0.71073 \AA$ ) at $150 \mathrm{~K}$. The SUPERFLIP72 program was employed for dealing with the collected data and refinement of data was achieved through the SHELX-97 and OLEX2 programs. Molecular weights and polydispersity index (PDI) of polyisoprene were undertaken by gel permeation chromatography (GPC, Viscotek VE2001 GPC, Viscotek Corporation, Houston, TX, USA) at $35^{\circ} \mathrm{C}$ using a PL2MB500A column in THF at a flow rate of $1 \mathrm{~cm}^{3} \cdot \mathrm{min}^{-1} ; 50 \mu \mathrm{L}$ was injected using a Viscotek VE2001 GPC equipped with a Viscotek VE3580 Refractive Index detector using THF as the eluent. While high temperature gel permeation chromatography (HGPC, PL-GPC 220, Agilent Technologies, Palo Alto, CA, USA) was employed for polymerization using trichlorobenzene as the eluent and polystyrenes as standards. Isoprene was purchased from Aladdin Industrial Corporation (Shanghai, China), dried over $\mathrm{CaH}_{2}$ and distilled prior to use. 1-(pyridin-2-yl)-N-(4-(trifluoromethyl)phenyl)methanimine (L1), (E)- $N$-(2,6-difluorophenyl)-1-(pyridin-2-yl)methanimine (L2), (E)-2,4,4-Trimethyl- $N$-(pyridin-2ylmethylene)pentan-2-amine (L4) and 1-(pyridin-2-yl)- $N$-(2,4,6-(triphenyl)phenyl)methanimine (L5) are not commercially available and can be prepared using reported procedure [29-33]. Complexes 4a $\left(\mathrm{C}_{14} \mathrm{H}_{22} \mathrm{Cl}_{2} \mathrm{FeN}_{2}\right)$, 5a $\left(\mathrm{C}_{60} \mathrm{H}_{44} \mathrm{Cl}_{4} \mathrm{Fe}_{2} \mathrm{~N}_{4}\right)$ and $\mathbf{4 b}\left(\mathrm{C}_{14} \mathrm{H}_{22} \mathrm{Cl}_{2} \mathrm{CoN}_{2}\right)$, $5 \mathbf{b}\left(\mathrm{C}_{30} \mathrm{H}_{22} \mathrm{Cl}_{2} \mathrm{CoN}_{2}\right)$ were synthesized using reported routes $[27,28]$. All other reagents were purchased from commercial sources and used without further purification. Due to the paramagnetic properties of $\mathrm{Fe}$ (II) and Co(II) complexes, these complexes were mainly characterized by elemental analyses, TOF-MS-ES+ (the concrete graphical data see Supplementary Materials, Figures S5-S10) and Attenuated total reflection-infrared spectroscopy (ATR-IR) unless otherwise noted.

\subsection{Experimental Methods}

\subsubsection{Synthesis of 1-(Pyridin-2-yl)-N-(2,4,6-trifluorophenyl)methanimine (L3)}

Note: The L1, L2, L4 and $\mathbf{L} 5$ are known compounds and can be prepared using reported procedure. However, the procedure adopted for the synthesis of $\mathbf{L} 3$ is slightly different in the context of purification process and can be prepared in the following procedure. To a solution of 2-pyridinecarboxaldehyde $(1.00 \mathrm{~g}, 0.89 \mathrm{~mL}, 6.80 \mathrm{mmol})$ in $\mathrm{CH}_{2} \mathrm{Cl}_{2}(10 \mathrm{~mL}), 2,4,6$-trifluoroaniline $(0.72 \mathrm{~g}, 6.73 \mathrm{mmol})$ was added. The reaction mixture was heated to reflux for $12 \mathrm{~h}$ with azeotropic removal of water using a Dean-Stark 
trap. On completion of the reaction (checked by TLC), the reaction mixture concentrated under reduced pressure and the residue was purified by recrystallization using hexane at $0{ }^{\circ} \mathrm{C}$ afforded $\mathbf{L} 3$ as colorless solid $(0.81 \mathrm{~g}, 50.5 \%$ yield $)$.

NMR Spectroscopy: ${ }^{1} \mathrm{H}$ NMR $\left(400 \mathrm{MHz}, \mathrm{CDCl}_{3}, 298 \mathrm{~K}\right), \delta: 8.75(\mathrm{~s}, 1 \mathrm{H}), 8.72-8.71(\mathrm{~m}, 1 \mathrm{H}), 8.25(\mathrm{~d}$, $J=7.8 \mathrm{~Hz}, 1 \mathrm{H}), 7.85-7.80(\mathrm{~m}, 1 \mathrm{H}), 7.41-7.38(\mathrm{~m}, 1 \mathrm{H}), 6.79-6.74(\mathrm{~m}, 2 \mathrm{H}) \mathrm{ppm} .{ }^{13} \mathrm{C}\left\{{ }^{1} \mathrm{H}\right\} \mathrm{NMR}(100 \mathrm{MHz}$, $\left.\mathrm{CDCl}_{3}, 298 \mathrm{~K}\right), \delta:$ 167.3-167.2 (m), 161.1-160.8 (t), 158.6-158.3 (t), 156.9-156.7 (m), 154.4-154.2 (m), 149.9 (s), 136.8 (s), 125.9 (s), 121.9 (s), 101.2-100.6 (m) ppm. ${ }^{19} \mathrm{~F}$ NMR (376 MHz, CDCl $\left.3,298 \mathrm{~K}\right), \delta$ : $-111.31-111.38(\mathrm{~m}, 1 \mathrm{~F}),-119.98-120.01(\mathrm{~m}, 2 \mathrm{~F}) \mathrm{ppm}$. HRMS-ESI $(\mathrm{m} / \mathrm{z})$ : Calcd for $\left[\mathrm{C}_{12} \mathrm{H}_{7} \mathrm{~F}_{3} \mathrm{~N}_{2}+\mathrm{H}\right]$, 237.0634. Found, 237.0631; Calcd. for $\left[\mathrm{C}_{12} \mathrm{H}_{7} \mathrm{~F}_{3} \mathrm{~N}_{2}+\mathrm{Na}\right]$, 259.0454. Found, 259.0454.

\subsubsection{Synthesis of Iminopyridine Fe(II) Complexes 1a, 2a, 3a}

\section{Synthesis of $\mathbf{1 a}$}

In a glovebox, a solution of ligand $\mathbf{L 1}(125.0 \mathrm{mg}, 0.50 \mathrm{mmol})$ in $\mathrm{CH}_{2} \mathrm{Cl}_{2}(8 \mathrm{~mL})$ was added to anhydrous $\mathrm{FeCl}_{2}(63.3 \mathrm{mg}, 0.50 \mathrm{mmol})$ in $25 \mathrm{~mL}$ Schlenk flask. The mixture was stirred for $48 \mathrm{~h}$ at room temperature. The precipitate was collected by filtration in argon atmosphere, washed with distilled hexane $(10 \mathrm{~mL} \times 2)$ and dried under vacuum to obtain gray solid $1 \mathrm{a}(112.6 \mathrm{mg}, 59.8 \%$ yield $)$. TOF-MS-ES+ $(\mathrm{m} / z)$ : calcd. for $\mathrm{C}_{26} \mathrm{H}_{18} \mathrm{ClF}_{6} \mathrm{FeN}_{4}$ : 591.0474, found: 591.0487 [M - Cl] ${ }^{+}$. Anal. calcd. for $\mathrm{C}_{13} \mathrm{H}_{9} \mathrm{Cl}_{2} \mathrm{~F}_{3} \mathrm{FeN}_{2}$ : $\mathrm{C}, 41.43 ; \mathrm{H}, 2.41 ; \mathrm{N}, 7.43$; found: $\mathrm{C}, 41.41 ; \mathrm{H}, 2.65 ; \mathrm{N}, 7.11$. ATR-IR $\left(\mathrm{cm}^{-1}\right): 3070,1592$ $v(\mathrm{C}=\mathrm{N}), 1446,1322,1160,1125,1069,856,828,786$.

\section{Synthesis of $\mathbf{2 a}$}

In a glovebox, a solution of ligand $\mathbf{L} 2(150.0 \mathrm{mg}, 0.69 \mathrm{mmol})$ in $\mathrm{CH}_{2} \mathrm{Cl}_{2}(8 \mathrm{~mL})$ was added to anhydrous $\mathrm{FeCl}_{2}(87.1 \mathrm{mg}, 0.69 \mathrm{mmol})$ in $25 \mathrm{~mL}$ Schlenk flask. The reaction was stirred for $48 \mathrm{~h}$ at room temperature. The precipitate was collected by filtration in argon atmosphere, washed with distilled hexane $(10 \mathrm{~mL} \times 2)$ and dried under vacuum to obtain atropurpureus solid $2 \mathbf{2 a}(168.1 \mathrm{mg}$, 73.0\% yield). TOF-MS-ES+ $(\mathrm{m} / \mathrm{z})$ : calcd. for $\mathrm{C}_{24} \mathrm{H}_{16} \mathrm{ClF}_{4} \mathrm{FeN}_{4}: 527.0350$, found: $527.0359[\mathrm{M}-\mathrm{Cl}]^{+}$. ATR-IR $\left(\mathrm{cm}^{-1}\right)$ : 3044, 1639, $1598 v(\mathrm{C}=\mathrm{N}), 1471,1304,960,809,779$. Note: We have performed the elemental analysis of $\mathbf{2 a}$, the obtained value is beyond the requirement of publishable results. Anal. calcd. for $\mathrm{C}_{12} \mathrm{H}_{8} \mathrm{Cl}_{2} \mathrm{~F}_{2} \mathrm{FeN}_{2}$ : C, 41.78; $\mathrm{H}, 2.34 ; \mathrm{N}, 8.12$; found: $\mathrm{C}, 39.72 ; \mathrm{H}, 3.51 ; \mathrm{N}, 7.47$.

Synthesis of $\mathbf{3 a}$

In a glovebox, a solution of ligand $\mathbf{L 3}(200.0 \mathrm{mg}, 0.85 \mathrm{mmol})$ in $\mathrm{CH}_{2} \mathrm{Cl}_{2}(8 \mathrm{~mL})$ was added to anhydrous $\mathrm{FeCl}_{2}(120.1 \mathrm{mg}, 0.85 \mathrm{mmol})$ in $25 \mathrm{~mL}$ Schlenk flask. The reaction mixture was stirred for $48 \mathrm{~h}$ at room temperature. The precipitate was collected by filtration in argon atmosphere, washed with distilled hexane $(10 \mathrm{~mL} \times 2)$ and dried under vacuum to obtain purple solid $3 a(96.2 \mathrm{mg}, 31.3 \%$ yield). TOF-MS-ES+ $(\mathrm{m} / z)$ : calcd. for $\mathrm{C}_{24} \mathrm{H}_{14} \mathrm{ClF}_{6} \mathrm{FeN}_{4}$ : 563.0161 , found: 563.0170 [M - Cl] ${ }^{+}$. ATR-IR $\left(\mathrm{cm}^{-1}\right)$ : 3034, 1626, $1598 \vee(\mathrm{C}=\mathrm{N}), 1502,1455,1446,1121,1044,836,819$, 778. Note: We have performed the elemental analysis of $3 \mathbf{a}$, the obtained value is beyond the requirement of publishable results. Anal. calcd. for $\mathrm{C}_{12} \mathrm{H}_{7} \mathrm{Cl}_{2} \mathrm{~F}_{3} \mathrm{FeN}_{2}$ : C, 39.71; $\mathrm{H}, 1.94 ; \mathrm{N}, 7.72$; found: $\mathrm{C}, 38.47 ; \mathrm{H}, 2.23 ; \mathrm{N}, 7.42$. Single crystal suitable for $\mathrm{X}$-ray diffraction analysis was obtained from concentrated acetonitrile solutions of complex 3a layered with hexane at $-35^{\circ} \mathrm{C}$.

\subsubsection{Synthesis of Iminopyridine Co(II) Complexes $\mathbf{1} \mathbf{b}, \mathbf{2} \mathbf{b}, \mathbf{3} \mathbf{b}$}

Synthesis of $\mathbf{1 b}$

In a glovebox, a solution of ligand $\mathbf{L 1}(125.0 \mathrm{mg}, 0.48 \mathrm{mmol})$ in THF $(8 \mathrm{~mL})$ was added to anhydrous $\mathrm{CoCl}_{2}(64.9 \mathrm{mg}, 0.48 \mathrm{mmol})$ in $25 \mathrm{~mL}$ Schlenk flask. The reaction was stirred for $48 \mathrm{~h}$ at room temperature. The precipitate was collected by filtration in argon atmosphere, washed with distilled hexane $(10 \mathrm{~mL} \times 2)$ and dried under vacuum to obtain green solid $\mathbf{1 b}(141.1 \mathrm{mg}, 74.3 \%$ yield $)$. 
TOF-MS-ES+ $(m / z)$ : calcd. for $\mathrm{C}_{26} \mathrm{H}_{18} \mathrm{ClCoF}_{6} \mathrm{~N}_{4}$ : 594.0456, found: 594.0463 [M $\left.-\mathrm{Cl}\right]^{+}$. Anal. calcd. for $\mathrm{C}_{13} \mathrm{H}_{9} \mathrm{Cl}_{2} \mathrm{~F}_{3} \mathrm{CoN}_{2}$ : C, 41.08; $\mathrm{H}, 2.39 ; \mathrm{N}, 7.37$; found: $\mathrm{C}, 41.87 ; \mathrm{H}, 2.84 \mathrm{~N}, 7.98$. ATR-IR $\left(\mathrm{cm}^{-1}\right)$ : 3066, $1611,1597 v(\mathrm{C}=\mathrm{N}), 1323,1166,1123,1066,847,778$.

Synthesis of $\mathbf{2 b}$

In a glovebox, a solution of ligand $\mathbf{L} 2(150.0 \mathrm{mg}, 0.69 \mathrm{mmol})$ in THF $(8 \mathrm{~mL})$ was added to anhydrous $\mathrm{CoCl}_{2}(89.3 \mathrm{mg}, 0.69 \mathrm{mmol})$ in $25 \mathrm{~mL}$ Schlenk flask. The reaction was stirred for $48 \mathrm{~h}$ at room temperature. The precipitate was collected by filtration in argon atmosphere, washed with distilled hexane $(10 \mathrm{~mL} \times 2)$ and dried under vacuum to obtain blackish green solid $\mathbf{2 b}(216.0 \mathrm{mg}$, 90.3\% yield). TOF-MS-ES+ (m/z): calcd. for $\mathrm{C}_{24} \mathrm{H}_{16} \mathrm{ClCoF}_{4} \mathrm{~N}_{4}: 530.0331$, found: $530.0326[\mathrm{M}-\mathrm{Cl}]^{+}$. Anal. calcd. for $\mathrm{C}_{12} \mathrm{H}_{8} \mathrm{Cl}_{2} \mathrm{~F}_{2} \mathrm{CoN}_{2}: \mathrm{C}, 41.41 ; \mathrm{H}, 2.32 ; \mathrm{N}, 8.05$; found: $\mathrm{C}, 41.71 ; \mathrm{H}, 2.28 ; \mathrm{N}, 7.51$. ATR-IR $\left(\mathrm{cm}^{-1}\right)$ : 3072, 1637, $1599 \vee(\mathrm{C}=\mathrm{N}), 1472,1239,1013,814,776$. Single crystal suitable for X-ray diffraction analysis was obtained from concentrated acetonitrile solutions of complex $\mathbf{2 b}$ layered with hexane at $-35^{\circ} \mathrm{C}$.

\section{Synthesis of $\mathbf{3 b}$}

In a glovebox, a solution of ligand $\mathbf{L 3}(150.0 \mathrm{mg}, 0.64 \mathrm{mmol})$ in THF $(8 \mathrm{~mL})$ was added to anhydrous $\mathrm{CoCl}_{2}(82.5 \mathrm{mg}, 0.64 \mathrm{mmol})$ in $25 \mathrm{~mL}$ Schlenk flask. The reaction was stirred for $48 \mathrm{~h}$ at room temperature. The precipitate was collected by filtration in argon atmosphere, washed with distilled hexane $(10 \mathrm{~mL} \times 2)$ and dried under vacuum to obtain emerald green solid $\mathbf{3 b}(190.1 \mathrm{mg}$, $81.8 \%$ yield). TOF-MS-ES+ $\left(\mathrm{m} / \mathrm{z}\right.$ ): calcd. for $\mathrm{C}_{24} \mathrm{H}_{14} \mathrm{Cl}_{3} \mathrm{Co}_{2} \mathrm{~F}_{6} \mathrm{~N}_{4}: 694.8853$, found: $694.8864[\mathrm{M}-\mathrm{Cl}]^{+}$. Anal. calcd. for $\mathrm{C}_{12} \mathrm{H}_{7} \mathrm{Cl}_{2} \mathrm{~F}_{3} \mathrm{CoN}_{2}$ : C, 39.38; $\mathrm{H}, 1.93 ; \mathrm{N}, 7.65$; found: $\mathrm{C}, 39.87 ; \mathrm{H}, 2.46 ; \mathrm{N}, 6.88$. ATR-IR $\left(\mathrm{cm}^{-1}\right)$ : 3067, 1637, $1598 \vee(\mathrm{C}=\mathrm{N}), 1500,1452,1124,1047,999,850,778$. Single crystal suitable for X-ray diffraction analysis was obtained from concentrated acetonitrile solutions of complex $\mathbf{3 b}$ layered with hexane at $-35{ }^{\circ} \mathrm{C}$.

\subsubsection{General Procedure for Isoprene Polymerization}

In a typical experiment, the reactor was heated, dried in a vacuum, and recharged with nitrogen for three times. When the reactor cooled down, an aluminum cocatalyst, toluene $(5 \mathrm{~mL})$, isoprene ( $2 \mathrm{~mL}, 20 \mathrm{mmol}$ ) and a solution of $\mathrm{Fe}(\mathrm{II})$ or $\mathrm{Co}(\mathrm{II})$ complexes $(8 \mu \mathrm{mol})$ in $1 \mathrm{~mL} \mathrm{CH}_{2} \mathrm{Cl}_{2}$ added into the reactor in sequence manner. The reaction was employed for $2 \mathrm{~h}$ and was then quenched with a diluted $\mathrm{HCl}$ solution of methanol $(\mathrm{MeOH} / \mathrm{HCl}=50 / 1)$. The polymer was collected by filtration and washed with ethanol several times and dried at room temperature for $24 \mathrm{~h}$ under vacuum.

For ternary system, a slightly different method of polymerization was used. A $25 \mathrm{~mL}$ Schlenk reactor was heated, dried in a vacuum, and recharged with nitrogen for three times. On cooling the reactor, $\mathrm{Fe}(\mathrm{II})$ or $\mathrm{Co}(\mathrm{II})$ complexes $(8 \mu \mathrm{mol})$ in $2 \mathrm{~mL}$ toluene, MAO $(40 \mu \mathrm{mol})$ in $1 \mathrm{~mL}$ toluene were added. The reaction mixture was stirred for $2 \mathrm{~min}$ and $\left[\mathrm{Ph}_{3} \mathrm{C}\right]\left[\mathrm{B}\left(\mathrm{C}_{6} \mathrm{~F}_{5}\right)_{4}\right](7.4 \mathrm{mg}, 8 \mu \mathrm{mol})$ was added as a solution in toluene $(2 \mathrm{~mL})$. The reaction mixture was stirred for $2 \mathrm{~min}$ and isoprene $(1 \mathrm{~mL}, 10 \mathrm{mmol})$ was added and stirred for $2 \mathrm{~h}$ at room temperature. The polymerization was quenched with a diluted $\mathrm{HCl}$ solution of methanol $(\mathrm{MeOH} / \mathrm{HCl}=50 / 1)$. The polymer was collected by filtration and washed with ethanol several times and dried at room temperature for $24 \mathrm{~h}$ under vacuum.

\section{Results and Discussion}

\subsection{The Synthesis and Characterization of Iminopyridine Ligands and Corresponding Fe(II) and Co(II) Complexes}

Ligand precursors were prepared by the condensation reaction of 2-pyridinecarboxaldehyde with arylamine in dichloromethane at refluxed temperature (Scheme 2). The desired compounds were purified through recrystallization in hexane (L1, L3), reduced pressure distillation (L4) or column chromatography (L2, L5). Ligands L1, L2, L4, and L5 were confirmed according to the 
references [29-33] and novel ligand L3 was characterized by ${ }^{1} \mathrm{H}$ NMR, ${ }^{13} \mathrm{C}$ NMR, ${ }^{19} \mathrm{~F}$ NMR, and HRMS-ESI (See Supplementary Materials, Figures S1-S4).

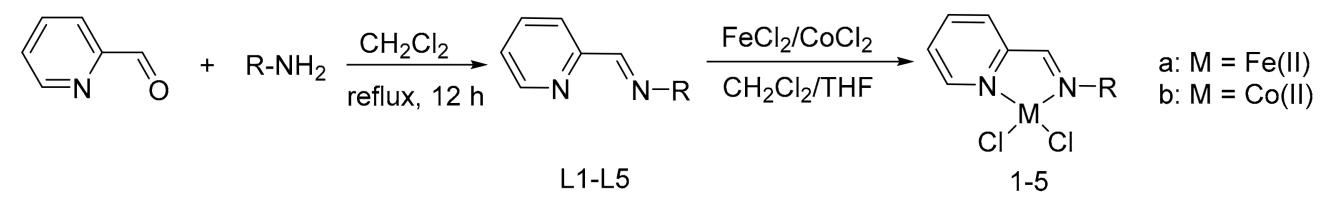

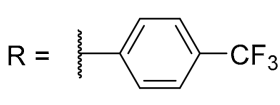

L1

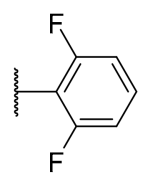

L2

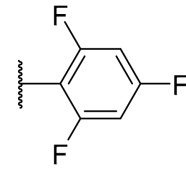

L3

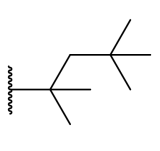

L4

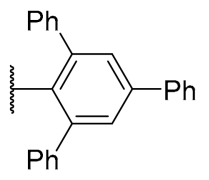

L5

Scheme 2. Synthesis of iminopyridine free ligands and the Fe(II) and Co(II) complexes.

The corresponding iminopyridine Fe(II) and Co(II) dichloride complexes containing fluorine substituents were synthesized by a reaction of the resulting iminopyridine ligand with one equivalent of anhydrous $\mathrm{FeCl}_{2}$ in $\mathrm{CH}_{2} \mathrm{Cl}_{2}$ or anhydrous $\mathrm{CoCl}_{2}$ in THF, respectively (Scheme 2). These complexes were characterized by ATR-IR, TOF-MS-ES+- and elemental analysis.

The structures of complexes $\mathbf{3} \mathbf{a}, \mathbf{2} \mathbf{b}$, and $\mathbf{3 b}$ were further characterized by $\mathrm{X}$-ray crystallographic analysis. The ORTEP drawings of Fe(II) complex $\mathbf{3} \mathbf{a}$ and $\mathrm{Co}(\mathrm{II})$ complexes $\mathbf{2} \mathbf{b}$ and $\mathbf{3} \mathbf{b}$ are shown in Figure 1 (Concrete crystallographic data see Supplementary Materials, Tables S7-S10). For these complexes, the ligands system adopts a cisoid conformation, which permits both pyridine nitrogen atoms and imine nitrogen atoms to coordinate to the metal atoms. Single crystal of Fe(II) complex 3a (See Figure 1a) was obtained by recrystallization from concentrated acetonitrile solutions of complex 3a layered with hexane at $-35^{\circ} \mathrm{C}$. The solid state crystal structure analysis shows that the complex $3 a$ adopts distorted octahedral coordination geometry around the iron metal formed by two iminopyridine ligands and two terminal chlorine atoms. And the imine nitrogen atom (N2) and $\mathrm{Cl} 2$ occupy the axial coordination sites and the axial N2-Fe1-Cl2 angle exhibits a small non-linearity $\left(167.46(12)^{\circ}\right)$. The bond distances of Fe-N(iminoaryl) [Fe1-N2: 2.304(5) $\AA$, Fe1-N4: 2.322(5) $\AA$ ] and Fe-N(pyridyl) [Fe1-N1: 2.204(5) $\AA$, Fe1-N3: 2.215(5) $\AA$ )] are all longer than the corresponding Fe-N bond distances

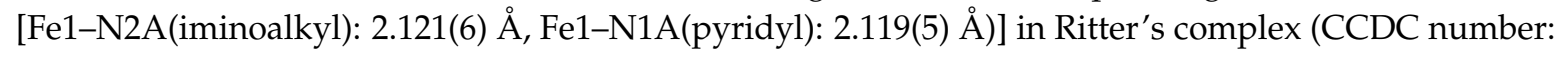
853130) [27], which may be supported that electron-withdrawing substituent (2,4,6-3F group in $3 \mathbf{a})$ reduces the electron density around the metal center and affects binding interaction between the metal and the coordination donor as well as the opening environment near the metal center. Complex $3 \mathbf{a}$ features a smaller N1-Fe1-N2 bond angle of $72.68(17)^{\circ}$, N3-Fe1-N4 bond angle of $72.58(17)^{\circ}$ and $\mathrm{Cl1}-\mathrm{Fe} 1-\mathrm{Cl} 2$ bond angle of $98.24(7)^{\circ}$ than N1A-Fe1-N2A bond angle of 78.3(2) ${ }^{\circ}$ and $\mathrm{Cl1} \mathrm{A}-\mathrm{Fe} 1-\mathrm{Cl} 2 \mathrm{~A}$ bond angle of $121.77(8)^{\circ}$ in Ritter's complex. These imply congestion around the Fe center. The $\mathrm{Fe}-\mathrm{Cl}$ bond lengths are about 2.396(19)-2.421(18) $\AA$ [Fe1-Cl1 2.4207(18) $\AA$; Fe1-Cl2 2.3958(19) $\AA$ ], which is longer than the Ritter's complex [Fe1-Cl1A 2.238(19) $\AA$; Fe1-Cl2A 2.244(2) ̊].

Single crystals of $\mathrm{Co}$ (II) complexes $\mathbf{2} \mathbf{b}$ and $\mathbf{3 b}$ were obtained by recrystallization from concentrated acetonitrile solutions of complexes layered with hexane at $-35^{\circ} \mathrm{C} . \mathbf{2} \mathbf{b}$ and $\mathbf{3 b}$ represented rare examples of chlorine bridged bimetallic cobalt complexes, which led to more distorted angles (average angles: $70.63^{\circ}$ for $\mathbf{2 b}$ and $70.83^{\circ}$ for $\mathbf{3 b}$ ) between the planes of aryl substituents at the imine nitrogen atom and the pyridine moiety than similar iminopyridine Co(II) complex (angle between the planes: $89.84^{\circ}$ ) as reported in the previous report [34]. Complex $\mathbf{2 b}$ (See Figure $1 \mathrm{~b}$ ) exists as an ion pair, $\left[\mathrm{L}_{2} \mathrm{CoCl}_{2}\right]\left[\mathrm{CoCl}_{3}\left(\mathrm{CH}_{3} \mathrm{CN}\right)\right]_{2}$ with cationic cobalt atom coordinated with two ligands and another two cobalt atoms each with three chlorine atoms and one acetonitrile molecule, respectively. The cation shows a chloride-bridged centrosymmetric dinuclear structure and two equivalent iminopyridine ligands coordinated with one cobalt atom. Each $\mathrm{Co}(\mathrm{II})$ ion is in a distorted octahedral geometry with 
the equatorial plane occupied by the two pyridine $\mathrm{N}$ atoms, one imine $\mathrm{N}$ atom and one bridging chlorine atom. The axial positions are occupied by the other imine $\mathrm{N}$ atom and the other bridging chlorine atom. The $\mathrm{Cl} 1-\mathrm{Co} 1-\mathrm{Cl} 2$ bond angle $\left(86.71(11)^{\circ}\right)$ is similar to the $\mathrm{Cl} 1-\mathrm{Co} 2-\mathrm{Cl} 2$ bond angle $\left(86.32(11)^{\circ}\right)$, and in the cation of complex $2 \mathbf{b}, \mathrm{Co}-\mathrm{N}$ bond distances and $\mathrm{Co}-\mathrm{Cl}$ bond distances are almost the same for both cobalt metal centers. An ion-paired complex $\left[\mathrm{L}_{2} \mathrm{Co}^{2+}\left[\mathrm{CoCl}_{4}\right]^{2-}\right.$ (A) was reported by D. Gong et al. in which $\mathrm{L}$ denotes tridentate $\mathrm{N}, \mathrm{N}, \mathrm{N}$ ligands [35]. In complex $\mathbf{2} \mathbf{b}, \mathrm{Co}-\mathrm{N}$ (pyridyl) bond distances range from 2.102(11) to 2.128(10) $\AA$ [Co1-N1 2.128(10) $\AA$; Co1-N3 2.121(10) ; Co2-N5 2.102(11) $\AA$; Co2-N7 2.120(10) $\AA$ ], which are slightly longer than the typical Co-N(pyridyl) bond distances of reported $\mathrm{Co}(\mathrm{II})$ complexes in the range of 2.032-2.035 $\AA$. Co-N(iminoaryl) bond distances are about 2.140(10)-2.178(10) $\AA$ [Co1-N2 2.140(10) $\AA$; Co1-N4 2.171(9) $\AA$; Co2-N6 2.149(10) $\AA$; Co2-N8 2.178(10) $\AA$ ], while those of Co-N(iminoaryl) are between 2.191-2.304 $\AA$. The Co-Cl bond distances in the cation of $\mathbf{2 b}$ are about 2.429(3)-2.453(3) $\AA$ [Co1-Cl1 2.429(3) $\AA$; Co1-Cl2 2.442(3) $\AA$; Co2-Cl1 2.453(3) $\AA$; Co2-Cl2 2.435(3) $\AA$ ]. The $\mathrm{Co}-\mathrm{Cl}$ bond distances are comparable to those of reported bisiminopyridine ligated Co(II) complexes with bond distances ranging from 2.244-2.284 $\AA$ [36,37]. The counter anions consist of two separated $\mathrm{CH}_{3} \mathrm{CN} \cdot \mathrm{CoCl}_{3}$, in which cobalt displays distorted tetrahedral geometry. Interestingly, there is a big difference in the bond distances of $\mathrm{C} \equiv \mathrm{N}$ coordinated to the $\mathrm{Co}$ atoms. In comparison with the bond distances of $\mathrm{C} \equiv \mathrm{N}$ triple bond of free $\mathrm{CH}_{3} \mathrm{CN}(\mathrm{C} \equiv \mathrm{N} 1.160 \AA)$ [38], the bond distances of $\mathrm{CH}_{3} \mathrm{CN}$ coordinated to $\mathrm{Co} 3$ is shortened (N9-C49 1.115(18) $\AA$ ), while the bond distances of $\mathrm{CH}_{3} \mathrm{CN}$ coordinated to $\mathrm{Co} 4$ is almost intact (N10-C51 1.150(18) $\AA$ ). There are few examples of structurally characterized cobalt complexes containing one or two $\mathrm{XCoCl}_{3}$ fragments $(\mathrm{X}=\mathrm{Cl}, \mathrm{S})$. Recent publication from Braunstein and coworkers reported dinuclear cobalt complexes contained one $\mathrm{CoCl}$ moiety ligated with two ligands and one $\mathrm{CoCl}_{3}$ fragment coordinated by $\mathrm{S}$ atom of the ligand (Figure S44) [39]. In the anionic fragment, the Co center ( $\mathrm{Co} 2)$ adopts a distorted tetrahedral coordination geometry with three similarly coordinated $\mathrm{Cl}$ ligands $[\mathrm{Co}-\mathrm{Cl}$ bond lengths are in the range 2.236(2)-2.246(2) $\AA$ ], which are slightly longer than the $\mathrm{Co}-\mathrm{Cl}$ bond distances in the anion of $\mathbf{2 b}$

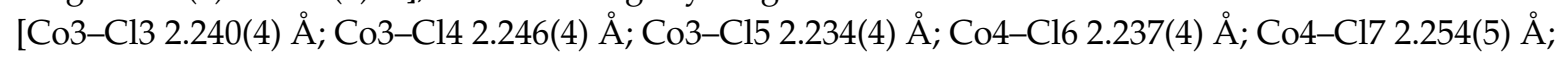

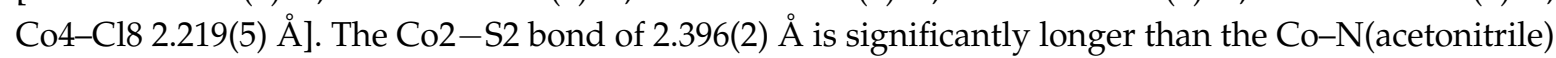

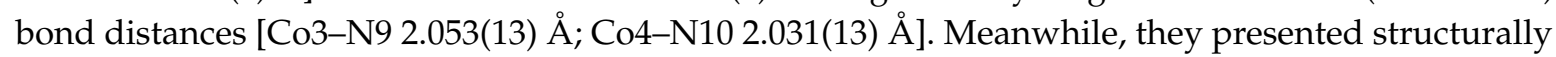
characterized zwitterionic cobalt complexes with anionic cobalt(II) centers in the form of $[\mathrm{L}] \mathrm{CoCl}_{3}$ and $[\mathrm{L}]_{2} \mathrm{CoCl}_{4}$ (Figure S44). The anionic $\mathrm{Co}$ (II) center of $[\mathrm{L}] \mathrm{CoCl}_{3}$ displays a distorted tetrahedral environment with $\mathrm{Co}-\mathrm{Cl}$ bond distances ranging from 2.233(8) (Cl2) to 2.264(8) (Cl3) $\AA$, slightly longer to those found in $\mathbf{2 b}$ [2.219(5)-2.246(4) $\AA$ ]. Interestingly, The $\mathrm{Co}-\mathrm{Cl}$ bond distances of anionic $\mathrm{Co}(\mathrm{II})$ center of $[\mathrm{L}]_{2} \mathrm{CoCl}_{4}$ range from 2.257(6)-2.293(5) $\AA$, which are much longer than those found in $\mathbf{2 b}$. The angles involving $\mathrm{N}$ of acetonitrile are in the range of $102.7(4)^{\circ}$ [N9-Co3-Cl3] to $109.6(4)^{\circ}$ [N9-Co3-Cl5], which are broader than those involving only chloride and the cobalt center [between $\mathrm{Cl} 5-\mathrm{Co} 3-\mathrm{Cl} 4$ $111.92(17)^{\circ}$ and $\left.\mathrm{Cl} 5-\mathrm{Co} 3-\mathrm{Cl} 3113.70(18)^{\circ}\right]$. Compared with complex $3 \mathbf{b}$, the replacement of chlorines by two ligands on the second cobalt metal center can be explained that two terminal chlorines are displaced by the less electron-withdrawing ligand $\mathbf{L 2}$, the leaving $\mathrm{Cl}$ anion is captured by $\mathrm{CoCl}_{2}$ and $\mathrm{CH}_{3} \mathrm{CN}$, existed in the form of $\mathrm{CH}_{3} \mathrm{CN} \cdot \mathrm{CoCl}_{3}$.

Complex $\mathbf{3 b}$ (See Figure 1c) features a chloride-bridged dinuclear structure as one cobalt ion is in a distorted octahedral coordination geometry while the other is in a distorted tetrahedral environment. In Co1 metal center, two equivalent iminopyridine ligands coordinated with it, the equatorial plane is occupied by pyridine nitrogen atom (N1, N3), imine nitrogen atom $\mathrm{N} 2$ and $\mathrm{Cl} 1$. The axial positions are coordinated by the imine nitrogen atom $\mathrm{N} 4$ and $\mathrm{Cl} 2$, which exhibits a small non-linearity [the $\mathrm{N} 4-\mathrm{Co} 1-\mathrm{Cl} 2$ bond angle is $171.61(13)^{\circ}$ ]. The N1-Co1-N2 bond angle is $77.4(2)^{\circ}$, and the N3-Co1-N4 bond angle is $76.76(18)^{\circ}$, which leads to a big block in $\mathrm{Co} 1$ metal center. The Co1-Cl bond lengths are 2.4647(17) $\AA$ (Co1-Cl1) and 2.4881(16) $\AA$ (Co1-Cl2) and Cl1-Co1-Cl2 bond angle is 87.07(5) ${ }^{\circ}$. The central metal atom $\mathrm{Co} 2$ can be best described as distorted tetrahedral coordination geometry with $\mathrm{Cl} 2-\mathrm{Co} 2-\mathrm{Cl} 1$ angle of $94.32(6)^{\circ}$ and $\mathrm{Cl} 4-\mathrm{Co} 2-\mathrm{Cl} 3$ angle of $112.60(9)^{\circ}$. The $\mathrm{Co} 2-\mathrm{Cl} 1$ and $\mathrm{Co} 2-\mathrm{Cl} 2$ bond lengths [2.3289(16) $\AA$ and 2.3235(18) $\AA$ ] are shorter than the Co1-Cl1 and Co1-Cl2 bond lengths 
[2.4647(17) $\AA$ and 2.4881(16) $\AA$ ] while longer than the Co2-Cl3 and Co2-Cl4 [2.2302(18) $\AA$ and 2.209(2) $\AA$ ]. The imino C-N bond distances [N2-C1 1.296(8) $\AA$, N4-C13 1.267(7) $\AA$ ] are consistent with the typical characters of $\mathrm{C}=\mathrm{N}$ double bond although it is relatively shorter than those in the literature [40-42]. The Co1-Co2 distance of 3.367(8) $\AA$ is longer than those found in some dicobalt complexes and carbonyl cobalt compounds $[43,44]$.

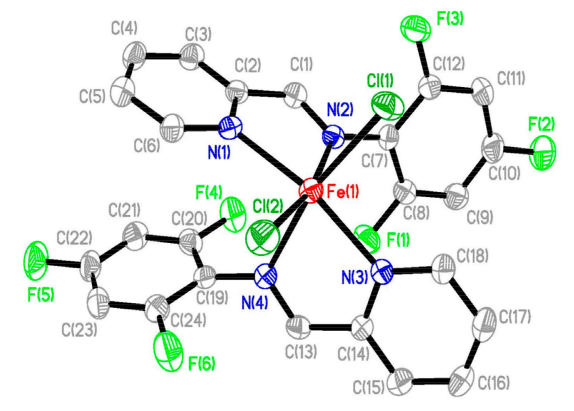

(a)

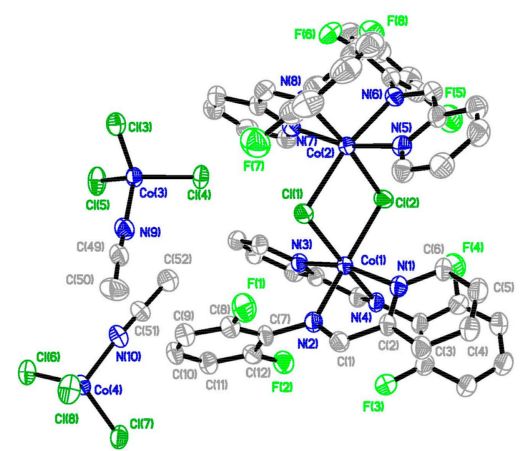

(b)

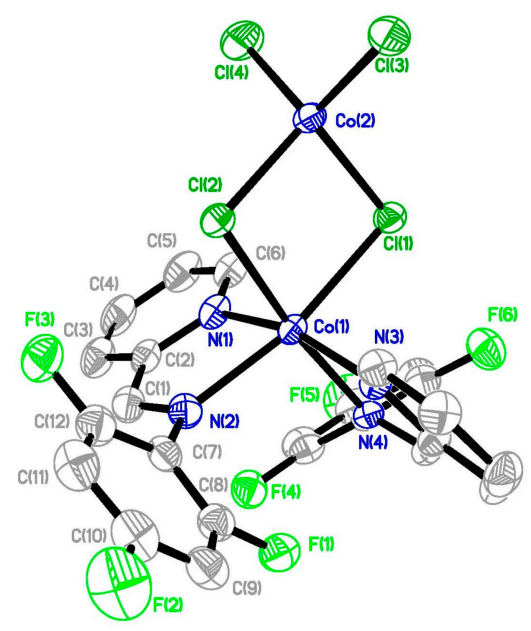

(c)

Figure 1. (a) ORTEP-type view of the structure of complex 3a, drawn at 30\% of probability. Hydrogen atoms and $\mathrm{CH}_{3} \mathrm{CN}$ molecule have been omitted for clarity; (b) ORTEP-type view of the structure of complex $2 \mathbf{b}$, drawn at $30 \%$ of probability. Hydrogen atoms and $\mathrm{CH}_{3} \mathrm{CN}$ molecule have been omitted for clarity; (c) ORTEP-type view of the structure of complex $3 \mathbf{b}$, drawn at $30 \%$ of probability. Hydrogen atoms and $\mathrm{CH}_{3} \mathrm{CN}$ molecule have been omitted for clarity.

\subsection{Isoprene Polymerization Studies}

\subsubsection{Polymerization of Isoprene with Fe(II) Catalysts}

A variety of alkylaluminum reagents $\left(\mathrm{MAO}, \mathrm{Al}(i-\mathrm{Bu})_{3}, \mathrm{AlEt}_{3}, \mathrm{AlEt}_{2} \mathrm{Cl}, \mathrm{AlEtCl}_{2}\right.$, and $\mathrm{EASC}$ (Ethylaluminum sesquichloride)) were screened as a cocatalyst in isoprene polymerization (See Supplementary Materials, Table S1) and MAO was chosen as the effective cocatalyst. The polymerization results are summarized in Table 1 (NMR Spectra and GPC characterizations of the representative polyisoprene see Supplementary Materials, Figures S11-S16 and S25-S29). 
Table 1. Iminopyridine Fe(II)-catalyzed isoprene polymerization employed methylaluminoxane (MAO) as cocatalyst ${ }^{\mathrm{a}}$.

\begin{tabular}{|c|c|c|c|c|c|c|c|c|}
\hline \multirow{2}{*}{ Entry } & \multirow{2}{*}{ Complex } & \multirow{2}{*}{ Yield (\%) } & \multicolumn{3}{|c|}{ Microstructure ${ }^{b}(\%)$} & \multirow{2}{*}{$\begin{array}{c}M_{n}{ }^{c} \\
\left(\times 10^{-4}\right)\end{array}$} & \multirow{2}{*}{ PDI $^{c}$} & \multirow{2}{*}{ Activity $^{\mathrm{d}}$} \\
\hline & & & cis-1,4 & trans $-1,4$ & 3,4 & & & \\
\hline 1 & 1a & $>99.0$ & 54 & - & 46 & 9.1 & 4.3 & 12.2 \\
\hline 2 & $2 a$ & 85.3 & 54 & - & 46 & 9.7 & 3.5 & 7.2 \\
\hline 3 & $3 a$ & 32.7 & 56 & - & 44 & 19.0 & 2.1 & 2.8 \\
\hline 4 & $4 a$ & 10.9 & - & 90 & 10 & $\begin{array}{c}62.7 \\
0.4\end{array}$ & $\begin{array}{l}2.1 \\
1.7\end{array}$ & 0.9 \\
\hline 5 & $5 a$ & 21.1 & 65 & - & 35 & 6.1 & 1.5 & 1.8 \\
\hline
\end{tabular}

${ }^{a}$ polymerization condition: Isoprene $2 \mathrm{~mL}$, complex $8 \mu \mathrm{mol}, \mathrm{Al} / \mathrm{Fe}=500,25{ }^{\circ} \mathrm{C}$, toluene $5 \mathrm{~mL}$, reaction time $2 \mathrm{~h}$; ${ }^{\mathrm{b}}$ determined by ${ }^{1} \mathrm{H}$ NMR and ${ }^{13} \mathrm{C}$ NMR; ${ }^{\mathrm{c}}$ determined by gel permeation chromatograph (GPC); $\mathrm{d} 10^{4} \mathrm{~g} \cdot(\mathrm{mol} \text { of } \mathrm{Fe})^{-1} \cdot(\mathrm{h})^{-1}$.

The fluorinated aryl moiety significantly influenced the catalytic performances of the complexes. The fluorinated aryl-substituted complexes 1a-3a produced polymers at higher yields (32.7-99.0\%) than the reported complexes $\mathbf{4 a - 5 a}(10.9-21.1 \%)$ under the same condition. In Fe(II)/MAO binary system, complex 1a bearing $4-\mathrm{CF}_{3}$ moiety exhibited the highest yield but with a relatively lower molecular weight and broad molecular weight distribution (Table 1, entry 1). Complex 2a having 2,6-2F moiety gave slightly lower activity with a higher molecular weight and narrow molecular weight distribution (Table 1, entry 2). In contrast, complex 3a with 2,4,6-3F showed the lowest activity with a higher molecular weight and narrower molecular weight distribution (Table 1, entry 3). It is proposed that introducing electron withdrawing group can reduce the electron density on the metal center and the increased Lewis acidic character facilitates the coordination of isoprene monomer, leading to the increment of chain propagation rate. The lower molecular weight of polyisoprene generated with complex 1a may be ascribed to a faster chain transfer process. Furthermore, in Fe(II)/MAO system, the ratio between cis-1,4-/3,4-units was not affected by the F substituents. Although this difference is not fully understood, it is clear that the cocatalyst may play an important role in determining the stereoselectivities.

Subsequently, complex 1a was used as a model catalyst to study the $\mathrm{Al} / \mathrm{M}$ ratio and catalyst loading influence on the isoprene polymerization. Gratifyingly, complex 1a can polymerize isoprene in full conversion within 10 min under our typical condition (See Supplementary Materials, Table S2, entry 1). Because of the poor solubility of the resultant polyisoprene, the molecular weight and molecular weight distribution cannot be obtained via GPC measurement. Decreasing the $\mathrm{Al} / \mathrm{M}$ ratio from to 500 to 10 resulted in a steady decline of obtained polymer yield but with a narrow PDI and an increase of the molecular weight. At $\mathrm{Al} / \mathrm{M}=500$, the stereoselectivity of the resultant polyisoprene was cis-1,4-/3,4- $=54 / 46$. Decreasing the $\mathrm{Al} / \mathrm{M}$ ratio and catalyst loading or increasing the $\mathrm{Al} / \mathrm{M}$ ratio with lower catalyst loading resulted in an inverse of the cis-1,4-/3,4- ratio (See Supplementary Materials, Table S2, entries 2, 3 and 6, 7; representative NMR spectra see Supplementary Materials, Figures S23 and S24). At very low $\mathrm{Al} / \mathrm{M}$ ratio $(\mathrm{Al} / \mathrm{Fe}=10)$, prolonging reaction time did not increase the polymer yield, which indicated a rapid deactivation process (See Supplementary Materials, Table S2, entries 3-5).

At $\mathrm{Al} / \mathrm{M}=500$, the catalyst loading of complex 1a can even be reduced to $1 \mu \mathrm{mol}$ to give reasonable yield of polyisoprene (See Supplementary Materials, Table S2, entry 6). Increasing reaction time resulted in little improvement on the polymer yield (See Supplementary Materials, Table S2, entries 8 and 9), which produced polyisoprene in $64.9 \%$ yield with a bimodal character. One active species generated high molecular weight of polyisoprene, the other generated low molecular weight of polyisoprene with narrow PDI. Prolonging the reaction time to $40 \mathrm{~min}$ and $1 \mathrm{~h}$ did not increase the yield of polyisoprene, which implied active species were rather sensitive and short-lived. However, based on the molecular weight of the obtained polyisoprene, it seems that the bimodal active species 
turned to unimodal species, which produced high molecular weight of polyisoprene along the reaction time [See Supplementary Materials, Table S2, entry 6: $9.3 \times 10^{4} / 1700$ (10 min), entry 8: $4.4 \times 10^{4}$ (40 min), and entry 9: $21.1 \times 10^{4}(1 \mathrm{~h})$ ]. Increasing the ratio of $\mathrm{Al} / \mathrm{Fe}$ from 500 to 1000, polyisoprene is obtained in $69.0 \%$ yield (See Supplementary Materials, Table S2, entry 7). It was concluded that large excess of MAO did not enhance the polymerization activity and stereoselectivity, while molecular weight and PDI showed an increasing trend.

For complex 1a, at very low catalyst loading $(1 \mu \mathrm{mol})$, we observed an increase of polymer yield when $\mathrm{Al} / \mathrm{M}$ ratio was increased from 500 to 1000 (See Supplementary Materials, Table S2, entries 6 and 7). Therefore, we systematically investigated higher $\mathrm{Al} / \mathrm{M}$ ratio on all the complexes $\mathbf{2 a}-\mathbf{5 a}$ (See Supplementary Materials, Table S3). The results showed that the polyisoprene yields increased with the increase of $\mathrm{Al} / \mathrm{Fe}$ ratio while stereoselectivity changed little when novel fluoro-substituted complexes 2a and 3a were employed. The increase of polyisoprene yield was highlighted by full conversion achieved in 2a system with an obvious increase of molecular weight $\left(M_{n}=22.3 \times 10^{4}\right)$. Similarly, at large excess of MAO, $\mathbf{4 a}$ and $5 \mathbf{a}$ showed a same trend in the yields while multi-modal polyisoprene was generated.

\subsubsection{Polymerization of Isoprene with Co(II) Catalysts}

Encouraged by the results in $\mathrm{Fe}$ (II) complexes catalyzed isoprene polymerization, further studies were carried out in $\mathrm{Co}$ (II) complexes using various common alkylaluminum reagents as cocatalysts. In iminopyridine $\mathrm{Co}(\mathrm{II})$-catalyzed isoprene polymerization, $\mathrm{MAO}, \mathrm{Al}(i-\mathrm{Bu})_{3}$, and $\mathrm{AlEt}_{3}$ showed an adverse effect on polymerization of isoprene (See Supplementary Materials, Table S4). However, $\mathrm{AlEt}_{2} \mathrm{Cl}$ was effective as cocatalyst. When the ratio of $\mathrm{Al} / \mathrm{Co}$ was 500 , no polymer was observed. Polymer appeared with the decrease of $\mathrm{Al} / \mathrm{Co}$ ratio (See Supplementary Materials, Table S5). After optimization of $\mathrm{Al} / \mathrm{M}$ ratio, $\mathrm{Al} / \mathrm{M}=10$ was chosen as the optimal condition in $\mathrm{Co}(\mathrm{II}) / \mathrm{AlEt}_{2} \mathrm{Cl}$ binary system (See Table 2; NMR Spectra and GPC characterizations of the representative polyisoprene see Supplementary Materials, Figures S17, S18 and S30-S34). Co(II) complexes $\mathbf{1 b}$ and $\mathbf{2 b}$ containing electron-withdrawing aryl substituents afforded polymers with higher molecular weights at moderate yields (Table 2, entries 1 and 2) than those by the complex Co(II) containing electron-donating alkyl substituents (Table 2, entry 4: $\mathrm{R}$ = octyl). This is similar with the trend observed in the Fe(II)/MAO systems. At this stage, there is no correlation between the electronic effect of the complexes and the resultant polyisoprene, especially in the stereoselectivity.

Table 2. Iminopyridine $\mathrm{Co}(\mathrm{II})$-catalyzed isoprene polymerization employed $\mathrm{AlEt}_{2} \mathrm{Cl}$ as cocatalyst ${ }^{\mathrm{a}}$.

\begin{tabular}{|c|c|c|c|c|c|c|c|}
\hline \multirow{2}{*}{ Entry } & \multirow{2}{*}{ Complex } & \multirow{2}{*}{ Yield (\%) } & \multicolumn{2}{|c|}{ Microstructure $^{b}(\%)$} & \multirow{2}{*}{$\begin{array}{c}M_{n}{ }^{c} \\
\left(\times 10^{-4}\right)\end{array}$} & \multirow{2}{*}{ PDI $^{c}$} & \multirow{2}{*}{ Activity } \\
\hline & & & cis- 1,4 & 3,4 & & & \\
\hline 1 & $1 b$ & 60.2 & 73 & 27 & 14.0 & 1.8 & 2.6 \\
\hline 2 & $2 b$ & 46.3 & 72 & 28 & 10.5 & 2.2 & 2.0 \\
\hline 3 & $3 b$ & 29.1 & 71 & 29 & 8.0 & 3.0 & 1.2 \\
\hline 4 & $4 b$ & 58.1 & 68 & 32 & 5.3 & 2.5 & 2.5 \\
\hline 5 & $5 b$ & 21.3 & 73 & 27 & 13.9 & 2.1 & 0.9 \\
\hline
\end{tabular}

${ }^{a}$ general condition: Isoprene $2 \mathrm{~mL}$, complex $8 \mu \mathrm{mol}, 25^{\circ} \mathrm{C}$, toluene $5 \mathrm{~mL}, \mathrm{Al} / \mathrm{Co}=10$, reaction time $4 \mathrm{~h}^{\mathrm{b}}{ }^{\mathrm{b}}$ determined by ${ }^{1} \mathrm{H}$ NMR and ${ }^{13} \mathrm{C}$ NMR; ${ }^{\mathrm{c}}$ determined by GPC; ${ }^{\mathrm{d}} 10^{4} \mathrm{~g} \cdot(\mathrm{mol} \text { of } \mathrm{Co})^{-1} \cdot(\mathrm{h})^{-1}$.

\subsubsection{The Ternary System of Iminopyridine Fe(II) and Co(II)-Catalyzed Isoprene Polymerization}

Raynaud et al. [27] reported a significant effect of introduction of a dealkylating reagent $\left(\left[\mathrm{Ph}_{3} \mathrm{C}\right]\left[\mathrm{B}\left(\mathrm{C}_{6} \mathrm{~F}_{5}\right)_{4}\right]\right)$ to the activated $\mathrm{Fe}(\mathrm{II})$ complexes using $\mathrm{Al}(i-\mathrm{Bu})_{3}$ and $\mathrm{AlEt}_{3}$ as cocatalyst. In our system, $\mathrm{MAO} /\left[\mathrm{Ph}_{3} \mathrm{C}\right]\left[\mathrm{B}\left(\mathrm{C}_{6} \mathrm{~F}_{5}\right)_{4}\right]$ cocatalysts were proved to be effective to generate polyisoprene (See Table 3; Screening experiment with various cocatalysts see Supplementary Materials, Table S6; NMR Spectra and GPC characterizations of the representative polyisoprene see Supplementary Materials, Figures S19-S22 and S35-S43). The Fe(II) complexes having fluorine substituents showed 
high activities (Table 3, entries 1-3). Furthermore, the ratio between trans-1,4-/3,4- units was not affected by the substituents pattern. It is assumed that the cocatalysts play an important role in determining the stereoselectivity. In Co(II)-catalyzed system, the fluorinated aryl moiety is electronically more withdrawing than the alkyl moiety, which can reduce the electron density on the metal center, leading to better monomer coordination and faster chain propagation. This is supported by the fact that $\mathrm{Co}(\mathrm{II})$ complex $\mathbf{3} \mathbf{b}$ bears the strongest electron-withdrawing substituent and displays the highest yield $(71.8 \%)$. In addition, the molecular weight of polyisoprene obtained by fluorine-substituted complexes $\mathbf{1} \mathbf{b}-\mathbf{3} \mathbf{b}$ is lower than the bulkier alkyl-substituted Co(II) complexes (4b) ( $\mathrm{R}=$ octyl) (Table 3, 1400 1600 vs. 1600). Probably, the steric environment of the alkyl moiety retards chain transfer reaction more effectively than less hindered fluorine substituted aryl moiety. We have to mention that as for the resultant polyisoprene, there were miscellaneous peaks in aromatic areas from ${ }^{1} \mathrm{H}$ NMR, which was speculated as by-product of toluene involved Friedel-Crafts reaction [45,46]. The change in stereoselectivity from binary system (cis-1,4-unit and 3,4-unit) to ternary system (trans-1,4-unit and 3,4-unit) is solely based on the cocatalysts. It is difficult to conclude the selectivity determining step because of the complexity of the cocatalyst and lack of reactive intermediates isolation. Furthermore, the isoprene coordination mode s-cis or s-trans (As is known for monoalkenes, the Cossee-Arlman mechanism is the main pathway for the formation of $\mathrm{C}-\mathrm{C}$ bonds in the polymerization of alkenes. Such mechanism is true of conjugated diene polymerization by homogeneous single site catalysts involves two steps, namely coordination of the incoming monomer to the catalyst active site and subsequent monomer insertion into a metal-carbon bond. However, the polymerization mechanism for conjugated dienes presents several peculiar aspects, mainly related to the type of bond between the transition metal of the catalyst and the growing chain. This bond is of a $\sigma$ type in monoalkene polymerizations, but is of the allylic type $\left(\eta^{3}\right)$ in conjugated diene polymerizations. Furthermore, the conjugated diene monomer can coordinate to the metal center assuming different conformations and hapticities: s-cis- $\eta^{4}$ (cis conformation around the single bond and coordination of the two double bonds), s-trans- $\eta^{4}$ (trans conformation around the single bond and coordination of the two double bonds), or s-trans- $\eta^{2}$ (trans conformation around the single bond and coordination of only one double bond. More mechanistic details see Supplementary Materials Figure S45) [47], migratory insertion into an $\eta^{2}$ - or $\eta^{4}$-coordinated isoprene, generation of syn- and anti-M-allyl intermediates, syn- to anti-rearrangements of the M-allyl complexes may all be relevant for selectivity [48-50].

Table 3. Iminopyridine Fe(II) and Co(II)-catalyzed isoprene polymerization ${ }^{\text {a }}$.

\begin{tabular}{|c|c|c|c|c|c|c|c|}
\hline \multirow{2}{*}{ Entry } & \multirow{2}{*}{ Complex } & \multirow{2}{*}{ Yield (\%) } & \multicolumn{2}{|c|}{ Microstructure $^{b}(\%)$} & \multirow{2}{*}{$\begin{array}{c}M_{n}{ }^{c} \\
\left(\times 10^{-3}\right)\end{array}$} & \multirow{2}{*}{ PDI $^{c}$} & \multirow{2}{*}{ Activity } \\
\hline & & & trans $-1,4$ & 3,4 & & & \\
\hline 1 & $1 a$ & 52.8 & 95 & 5 & 1.4 & 1.7 & 2.2 \\
\hline 2 & $2 a$ & 76.3 & 98 & 2 & 1.5 & 2.1 & 3.2 \\
\hline 3 & $3 a$ & 64.8 & 96 & 4 & 1.6 & 2.2 & 2.8 \\
\hline 4 & $4 a$ & 30.2 & 98 & 2 & 1.5 & 1.8 & 1.3 \\
\hline 5 & $5 a$ & trace & - & - & - & - & - \\
\hline 6 & $1 b$ & 19.3 & 96 & 4 & 1.6 & 1.5 & 0.8 \\
\hline 7 & $2 b$ & 39.7 & 98 & 2 & 1.4 & 1.7 & 1.7 \\
\hline 8 & $3 b$ & 71.8 & 95 & 5 & 1.4 & 1.9 & 3.1 \\
\hline 9 & $4 b$ & 19.6 & 98 & 2 & 1.6 & 1.5 & 0.8 \\
\hline 10 & $5 b$ & 32.2 & 98 & 2 & 1.2 & 1.6 & 1.4 \\
\hline
\end{tabular}

${ }^{a}$ general condition: Isoprene $1 \mathrm{~mL}, \mathrm{Fe}(\mathrm{II})$ or $\mathrm{Co}(\mathrm{II})$ complexes: $8 \mu \mathrm{mol}, 25^{\circ} \mathrm{C}, \mathrm{Al} / \mathrm{Fe}=\mathrm{Al} / \mathrm{Co}=5,\left[\mathrm{Ph}_{3} \mathrm{C}\right]\left[\mathrm{B}\left(\mathrm{C}_{6} \mathrm{~F}_{5}\right)_{4}\right]$ : $8 \mu \mathrm{mol}$, toluene $5 \mathrm{~mL}$, reaction time $2 \mathrm{~h} ;{ }^{b}$ determined by ${ }^{1} \mathrm{H}$ NMR and ${ }^{13} \mathrm{C}$ NMR; ${ }^{c}$ determined by GPC; $\mathrm{d} 10^{4} \mathrm{~g} \cdot(\mathrm{mol} \text { of Fe or } \mathrm{Co})^{-1} \cdot(\mathrm{h})^{-1}$.

\section{Conclusions}

In summary, we have investigated novel fluorinated aryl substituted iminopyridine Fe(II) and $\mathrm{Co}$ (II) complexes in isoprene polymerization. Higher polymer yield, high molecular 
weight and similar stereoselectivity (cis-1,4-/3,4-unit $\approx 1: 1)$ were obtained when binary Fe/MAO system was employed. This is the same trend with $\mathrm{Co} / \mathrm{AlEt}_{2} \mathrm{Cl}$ excepted the stereoselectivity (cis-1,4-/3,4-unit $\approx 7: 3$ ). In general, Fe(II) complexes exhibited higher activities than analogous $\mathrm{Co}(\mathrm{II})$ complexes. However, $\mathrm{Co}(\mathrm{II})$ complexes showed higher cis-1,4 selectivity than $\mathrm{Fe}(\mathrm{II})$ complexes under the same condition. When a dealkylating reagent $\left[\mathrm{Ph}_{3} \mathrm{C}\right]\left[\mathrm{B}\left(\mathrm{C}_{6} \mathrm{~F}_{5}\right)_{4}\right]$ was introduced in isoprene polymerization, low molecular weight $\left(M_{n}=1200 \sim 1700\right)$ and high trans-1,4 polyisoprene $(>95 \%)$ were prepared using either $\mathrm{Fe}(\mathrm{II})$ or $\mathrm{Co}$ (II) catalysts and MAO cocatalyst. In such system, the differences of catalytic behaviors between Fe(II) and Co(II) systems were not obvious. These studies demonstrated that iminopyridine complexes containing fluorine substituents tended to enhance the catalytic activity and led to a relatively higher yield of polyisoprene. Fe(II) complex (1a) containing $\mathrm{CF}_{3}$ substituent represented a rare example of highly active Fe(II) catalyst and relatively low catalyst loading $(1 \mu \mathrm{mol})$ in isoprene polymerization. In addition, it is observed that less amount of $\mathrm{AlEt}_{2} \mathrm{Cl}$ was required to initiate an effective isoprene polymerization in $\mathrm{Co} / \mathrm{AlEt}_{2} \mathrm{Cl}$ binary system. The stereoselectivity of polyisoprene was strongly dependent on the cocatalysts type and metal center. Further studies aiming at exploring the controllable polymerization using iminopyridine complexes and mechanistic studies are now in progress in our laboratory.

Supplementary Materials: The following are available online at http:/ / www.mdpi.com/2073-4360/10/9/934/s1, NMR spectra of the ligands L3 (Figures S1-S3), HRMS-ESI of L3 (Figure S4), TOF-MS-ES+ of Complexes (Figures S5-S10), NMR spectra of the representative polyisoprene (Figures S11-S24) and GPC curves of polyisoprene samples (Figures S25-S43), ion-paired cobalt complexes (Figure S44), Machanism of Formation of Polyisoprene (Figure S45), optimum condition screening polymerization (Tables S1-S6), crystal data of Fe(II) Complex 3a (CCDC number: 1830611), Co(II) Complex 2b (CCDC number: 1830608) and Co(II) Complex 3b (CCDC number: 1830612) (Tables S7-S10).

Author Contributions: Q.W. and X.W. developed the original idea and designed the experiments; G.Z. performed the major experiments; X.Z., M.Z., L.W. and C.J. assisted this work; P.W. dealt with single-crystal structures; G.Z. wrote the paper under the guidance of X.W. and Q.W.

Funding: This research was funded by "135" Projects Fund of CAS-QIBEBT Director Innovation Foundation, National Natural Science Foundation of China (NSFC, 21702215) and DICP\& QIBEBT United Foundation (UN 201701).

Acknowledgments: We gratefully acknowledge the generous support by the CAS Hundred Talents Program (Y5100719AL).

Conflicts of Interest: The authors declare no conflict of interest.

\section{References}

1. Ouardad, S.; Bakleh, M.-E.; Kostjuk, S.V.; Ganachaud, F.; Puskas, J.E.; Deffieux, A.; Peruch, F. Bio-inspired cationic polymerization of isoprene and analogues: State-of-the-art. Polym. Int. 2012, 61, 149-156. [CrossRef]

2. Horne, S.E.; Kiehl, J.P.; Shipman, J.J.; Folt, V.L.; Gibbs, C.F.; Willson, E.A.; Newton, E.B.; Reinhart, M.A.; Willson, E.A. Ameripol SN-A cis-1,4-polyisoprene. Ind. Eng. Chem. 1956, 48, 784-791. [CrossRef]

3. Ricci, G.; Sommazzi, A.; Masi, F.; Ricci, M.; Boglia, A.; Leone, G. Well-defined transition metal complexes with phosphorus and nitrogen ligands for 1,3-dienes polymerization. Coord. Chem. Rev. 2010, 254, 661-676. [CrossRef]

4. Wang, B.L.; Cui, D.M.; Lv, K. Highly 3,4-selective living polymerization of isoprene with rare earth metal fluorenyl N-heterocyclic carbene precursors. Macromolecules 2008, 41, 1983-1988. [CrossRef]

5. Kamienski, C.W. Lithium catalysis in industrial polymerization. Ind. Eng. Chem. 1965, 57, 38-55. [CrossRef]

6. Lopez-Sanchez, J.A.; Lamberti, M.; Pappalardo, D.; Pellecchia, C. Polymerization of conjugated dienes promoted by bis(phenoxyimino)titanium catalysts. Macromolecules 2003, 36, 9260-9263. [CrossRef]

7. Osakada, K.; Takeuchi, D. Coordination polymerization of dienes, allenes, and methylenecycloalkanes. Polym. Synth. 2004, 171, 137-194.

8. Zhang, L.X.; Suzuki, T.; Luo, Y.; Nishiura, M.; Hou, Z.M. Cationic alkyl rare-earth metal complexes bearing an ancillary bis(phosphinophenyl)amido ligand: A catalytic system for living cis-1,4-polymerization and copolymerization of isoprene and butadiene. Angew. Chem. Int. Ed. 2007, 46, 1909-1913. [CrossRef] [PubMed] 
9. Gao, W.; Cui, D.M. Highly cis-1,4 selective polymerization of dienes with homogeneous Ziegler-Natta catalysts based on NCN-pincer rare earth metal dichioride precursors. J. Am. Chem. Soc. 2008, 130, 4984-4991. [CrossRef] [PubMed]

10. Zhang, L.X.; Nishiura, M.; Yuki, M.; Luo, Y.; Hou, Z.M. Isoprene polymerization with yttrium amidinate catalysts: Switching the regio- and stereoselectivity by addition of AlMe . Angew. Chem. Int. Ed. 2008, 47, 2642-2645. [CrossRef] [PubMed]

11. Lv, K.; Cui, D.M. CCC-pincer bis(carbene) lanthanide dibromides. Catalysis on highlycis-1,4-selective polymerization of isoprene and active species. Organometallics 2010, 29, 2987-2993. [CrossRef]

12. Li, D.F.; Li, S.H.; Cui, D.M.; Zhang, X.Q. $\beta$-diketiminato rare-earth metal complexes. structures, catalysis, and active species for highly cis-1,4-selective polymerization of isoprene. Organometallics 2010, 29, 2186-2193. [CrossRef]

13. Nishiura, M.; Hou, Z.M. Novel polymerization catalysts and hydride clusters from rare-earth metal dialkyls. Nat. Chem. 2010, 2, 257-268. [CrossRef] [PubMed]

14. Britovsek, G.J.P.; Gibson, V.C.; Kimberley, B.S.; Maddox, P.J.; McTavish, S.J.; Solan, G.A.; White, A.J.P.; Williams, D.J. Novel olefin polymerization catalysts based on iron and cobalt. Chem. Commun. 1998, 849-850. [CrossRef]

15. Small, B.L.; Brookhart, M.; Bennett, A.M.A. Highly active iron and cobalt catalysts for the polymerization of ethylene. J. Am. Chem. Soc. 1998, 120, 4049-4050. [CrossRef]

16. Ricci, G. Polymerization of 1,3-dienes with iron complexes based catalysts Influence of the ligand on catalyst activity and stereospecificity. J. Mol. Catal. A Chem. 2003, 204-205, 287-293. [CrossRef]

17. Ricci, G.; Motta, T.; Boglia, A.; Alberti, E.; Zetta, L.; Bertini, F.; Arosio, P.; Famulari, A.; Meille, S.V. Synthesis, characterization, and crystalline structure of syndiotactic 1,2-polypentadiene: The trans polymer. Macromolecules 2005, 38, 8345-8352. [CrossRef]

18. Ricci, G.; Boglia, A.; Motta, T.; Bertini, F.; Boccia, A.C.; Zetta, L.; Alberti, E.; Famulari, A.; Arosio, P.; Meille, S.V. Synthesis and structural characterization of syndiotactictrans-1,2 and cis-1,2 polyhexadienes. J. Polym. Sci. A Polym. Chem. 2007, 45, 5339-5353. [CrossRef]

19. Ricci, G.; Leone, G.; Boglia, A.; Bertini, F.; Boccia, A.C.; Zetta, L. Synthesis and characterization of isotactic 1,2-poly(E-3-methyl-1,3-pentadiene). Some remarks about the influence of monomer structure on polymerization stereoselectivity. Macromolecules 2009, 42, 3048-3056. [CrossRef]

20. Ricci, G.; Leone, G.; Boglia, A.; Boccia, A.C.; Zetta, L. cis-1,4-alt-3,4 polyisoprene: Synthesis and characterization. Macromolecules 2009, 42, 9263-9267. [CrossRef]

21. He, A.H.; Wang, G.; Zhao, W.Z.; Jiang, X.B.; Yao, W.; Sun, W.H. High cis-1,4 polyisoprene or cis-1,4/3,4 binary polyisoprene synthesized using 2-(benzimidazolyl)-6-(1-(arylimino)ethyl)pyridine cobalt(II) dichlorides. Polym. Int. 2013, 62, 1758-1766. [CrossRef]

22. Takano, S.; Takeuchi, D.; Osakada, K.; Akamatsu, N.; Shishido, A. Dipalladium catalyst for olefin polymerization: Introduction of acrylate units into the main chain of branched polyethylene. Angew. Chem. Int. Ed. 2014, 53, 9246-9250. [CrossRef] [PubMed]

23. Dai, S.Y.; Sui, X.L.; Chen, C.L. Highly robust palladium(II) alpha-diimine catalysts for slow-chain-walking polymerization of ethylene and copolymerization with methyl acrylate. Angew. Chem. Int. Ed. 2015, 54, 9948-9953. [CrossRef] [PubMed]

24. Guo, L.H.; Dai, S.Y.; Sui, X.L.; Chen, C.L. Palladium and nickel catalyzed chain walking olefin polymerization and copolymerization. ACS Catal. 2015, 6, 428-441. [CrossRef]

25. Nakamura, A.; Ito, S.; Nozaki, K. Coordination-insertion copolymerization of fundamental polar monomers. Chem. Rev. 2009, 109, 5215-5244. [CrossRef] [PubMed]

26. Chen, E.Y.X. Coordination polymerization of polar vinyl monomers by single-site metal catalysts. Chem. Rev. 2009, 109, 5157-5214. [CrossRef] [PubMed]

27. Raynaud, J.; Wu, J.Y.; Ritter, T. Iron-catalyzed polymerization of isoprene and other 1,3-dienes. Angew. Chem. Int. Ed. 2012, 51, 11805-11808. [CrossRef] [PubMed]

28. Guo, L.H.; Jing, X.Y.; Xiong, S.Y.; Liu, W.J.; Liu, Y.L.; Liu, Z.; Chen, C.L. Influences of alkyl and aryl substituents on iminopyridine Fe(II)- and Co(II)-catalyzed isoprene polymerization. Polymers 2016, 8, 389. [CrossRef] 
29. Huang, Z.F.; Song, K.M.; Liu, F.S.; Long, J.M.; Hu, H.; Gao, H.Y.; Wu, Q. Synthesis and characterization of a series of 2-aminopyridine nickel(II) complexes and their catalytic properties toward ethylene polymerization. J. Polym. Sci. A Polym. Chem. 2008, 46, 1618-1628. [CrossRef]

30. Zai, S.B.; Gao, H.Y.; Huang, Z.F.; Hu, H.B.; Wu, H.; Wu, Q. Substituent effects of pyridine-amine nickel catalyst precursors on ethylene polymerization. ACS Catal. 2012, 2, 433-440. [CrossRef]

31. Hilt, G.; Janikowski, J.; Schwarzer, M.; Burghaus, O.; Sakow, D.; Bröring, M.; Drüschler, M.; Huber, B.; Roling, B.; Harms, K.; et al. Studies of electronic effects of modified pyridine-imine ligands utilized in cobalt-catalyzed meta-selective Diels-Alder reactions. J. Organomet. Chem. 2014, 749, 219-223. [CrossRef]

32. Iovel, I.; Golomba, L.; Belyakov, S.; Kemme, A.; Lukevics, E. Addition of $\mathrm{Me}_{3} \mathrm{SiCN}$ to trifluoromethyl derivates of $\mathrm{N}$-(pyridylmethylidene) anilines catalyzed by Lewis acids. Appl. Organomet. Chem. 2001, 15, 733-743. [CrossRef]

33. Diez, V.; Cuevas, J.V.; Garcia-Herbosa, G.; Aullon, G.; Charmant, J.P.H.; Carbayo, A.; Munoz, A. ${ }^{1}$ H NMR direct observation of enantiomeric exchange in palladium(II) and platinum(II) complexes containing $N, N^{\prime}$-bidentate aryl-pyridin-2-ylmethyl-amine ligands. Inorg. Chem. 2007, 46, 568-577. [CrossRef] [PubMed]

34. Dai, Q.Q.; Jia, X.Y.; Yang, F.; Bai, C.X.; Hu, Y.M.; Zhang, X.Q. Iminopyridine-based cobalt(II) and nickel(II) complexes: Synthesis, characterization, and their catalytic behaviors for 1,3-butadiene polymerization. Polymers 2016, 8, 12. [CrossRef]

35. Gong, D.; Jia, W.; Chen, T.; Huang, K.-W. Polymerization of 1,3-butadiene catalyzed by pincer cobalt(II) complexes derived from 2-(1-arylimino)-6-(pyrazol-1-yl)pyridine ligands. Appl. Catal. A Gen. 2013, 464-465, 35-42. [CrossRef]

36. Gong, D.; Wang, B.; Cai, H.; Zhang, X.; Jiang, L. Synthesis, characterization and butadiene polymerization studies of cobalt(II) complexes bearing bisiminopyridine ligand. J. Organomet. Chem. 2011, 696, 1584-1590. [CrossRef]

37. Nobbs, J.D.; Tomov, A.K.; Cariou, R.; Gibson, V.C.; White, A.J.; Britovsek, G.J. Thio-Pybox and Thio-Phebox complexes of chromium, iron, cobalt and nickel and their application in ethylene and butadiene polymerisation catalysis. Dalton Trans. 2012, 41, 5949-5964. [CrossRef] [PubMed]

38. Karakida, K.; Fukuyama, T.; Kuchitsu, K. Molecular-structures of hydrogen-cyanide and acetonitrile as studied by gas electron-diffraction. Bull. Chem. Soc. Jpn. 1974, 47, 299-304. [CrossRef]

39. Fliedel, C.; Rosa, V.; Vileno, B.; Parizel, N.; Choua, S.; Gourlaouen, C.; Rosa, P.; Turek, P.; Braunstein, P. Zwitterionic cobalt complexes with bis(diphenylphosphino)( $N$-thioether)amine assembling ligands: Structural, EPR, magnetic, and computational studies. Inorg. Chem. 2016, 55, 4183-4198. [CrossRef] [PubMed]

40. Jie, S.; Ai, P.; Li, B.G. Highly active and stereospecific polymerization of 1,3-butadiene catalyzed by dinuclear cobalt(II) complexes bearing 3-aryliminomethyl-2-hydroxybenzaldehydes. Dalton Trans. 2011, 40, 10975-10982. [CrossRef] [PubMed]

41. Zhang, Y.-M.; Lin, Q.; Wei, T.-B.; Zhang, D.-H.; Jie, S.-Y. Synthesis, structure and ethylene oligomerization behavior of non-symmetric bidentate neutral arylnickel(II) phosphine complexes. Inorg. Chim. Acta 2005, 358, 4423-4430. [CrossRef]

42. Du, J.L.; Han, L.Q.; Cui, Y.; Li, J.T.; Li, Y.; Sun, W.H. Synthesis, characterization, and ethylene oligomerization of 2,6-bis(imino)phenoxy cobalt complexes. Aust. J. Chem. 2003, 56, 703-706. [CrossRef]

43. Aggarwal, R.P.; Connelly, N.G.; Crespo, M.C.; Dunne, B.J.; Hopkins, P.M.; Orpen, A.G. Oxidatively induced alkyne rotation in dicobalt complexes-structural tests of molecular-orbital theory. J. Chem. Soc. Dalton Trans. 1992, 655-662. [CrossRef]

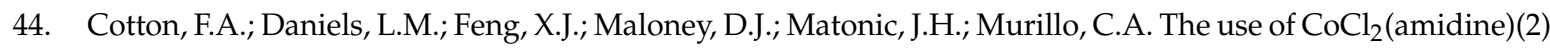
compounds in the synthesis of tetragonal lantern dicobalt compounds: Synthesis, structures and theoretical studies of $\mathrm{Co}-2(\mathrm{DPhF})(4)$ and the oxidized species Co-2(DPhBz)(4) $(+)\left(\mathrm{DPhF}=N, N^{\prime}\right.$-diphenylformamidinate, $\mathrm{DPhBz}=N, N^{\prime}$-diphenylbenzamidinate) 4. Inorg. Chim. Acta 1997, 256, 291-301.

45. Gaylord, N.G.; Švestka, M. Cyclo- and Cyclized Diene Polymers. XXI. Polymerization of Isoprene by Stable Carbonium Ion Salt Catalysts. J. Macromol. Sci. Part A Chem. 1969, 3, 897-909. [CrossRef]

46. Ouardad, S.; Deffieux, A.; Peruch, F. Polyisoprene synthesized via cationic polymerization: State of the art. Pure Appl. Chem. 2012, 84, 2065-2080. [CrossRef] 
47. Costabile, C.; Milano, G.; Cavallo, L.; Guerra, G. Stereoselectivity and chemoselectivity in Ziegler-Natta polymerizations of conjugated dienes. 1 . monomers with low-energy s-cis- $\eta^{4}$ coordination. Macromolecules 2001, 34, 7952-7960. [CrossRef]

48. Li, X.F.; Nishiura, M.; Hu, L.H.; Mori, K.; Hou, Z.M. Alternating and random copolymerization of isoprene and ethylene catalyzed by cationic half-sandwich scandium alkyls. J. Am. Chem. Soc. 2009, 131, 13870-13882. [CrossRef] [PubMed]

49. Kang, X.H.; Luo, Y.; Zhou, G.L.; Wang, X.B.; Yu, X.R.; Hou, Z.M.; Qu, J.P. Theoretical mechanistic studies on the trans-1,4-specific polymerization of isoprene catalyzed by a cationic La-Al binuclear complex. Macromolecules 2014, 47, 4596-4606. [CrossRef]

50. Chandran, D.; Kwak, C.H.; Ha, C.-S.; Kim, I. Polymerization of 1,3-butadiene by bis(salicylaldiminate)cobalt(II) catalysts combined with organoaluminium cocatalysts. Catal. Today 2008, 131, 505-512. [CrossRef]

(C) 2018 by the authors. Licensee MDPI, Basel, Switzerland. This article is an open access article distributed under the terms and conditions of the Creative Commons Attribution (CC BY) license (http://creativecommons.org/licenses/by/4.0/). 